\title{
Is the presence of Leptospira in the environment merely ran- dom? An epidemiological explanation based on serial analysis of water samples
}

\author{
Janith Warnasekara ${ }^{1}$, Shalka Srimantha ${ }^{1}$, Indika Senavirathna ${ }^{1,2},{ }^{2}$ Chamila Kappagoda ${ }^{1}$, Nirmani Farika ${ }^{1}$, Achala \\ Nawinna $^{3}$, Suneth Agampodi ${ }^{1}$
}

${ }^{1}$ Department of Community Medicine, Faculty of Medicine and Allied Sciences, Rajarata University of Sri Lanka

2Department of Biochemistry, Faculty of Medicine and Allied Sciences, Rajarata University of Sri Lanka

${ }^{3}$ Faculty of Medicine and Allied Sciences, Rajarata University of Sri Lanka

* Correspondence: jwarnasekara@yahoo.com; +94713181238

\begin{abstract}
Human leptospirosis cannot be investigated without studying zoonotic and environmental aspects of the disease. The objectives of this study are to explore the abundance of Leptospira in different climate zones of Sri Lanka and to describe the presence of Leptospira in the same water source at different time points. First, water and soil samples were collected from different parts of the country; second, water sampling continued only in the dry zone; and finally, serial sampling of water from ten open wells was performed at five different time points. Quantitative PCR of water and metagenomic sequencing of soil were performed to detect Leptospira. In the first component, 2 out of 12 water sites were positive, and both were situated in the wet zone. Very small quantities of the genus Leptospira were detected by metagenomic analysis of soil. Only 5 out of 26 samples were positive in the second component. Six, five, four, five, and six wells were positive in serial measurements of the third component. All wells were positive for at least one measurement, while only one well was positive for all measurements. Proximity to the tank and greater distances from the main road were significant risk factors associated with well positivity for Leptospira. The presence of Leptospira was not consistent, indicating the random abundance of Leptospira in the natural environment.
\end{abstract}

Keywords: Leptospirosis, Leptospira, water, random, metagenomic, epidemiology, soil, environment, survival, climate, zones, serial sampling

\section{Introduction}

Integrating human, animal and environmental health is essential in the control and prediction of zoonotic diseases. While investigations on animal and human interfaces are increasing, greater incorporation of environmental and ecosystem components is highlighted as a missing link in the One Health approach(1). Leptospirosis, a globally widespread and neglected tropical disease, also lacks adequate investigations linking animal and environmental factors to human infection. Various definitive and intermediate hosts, such as livestock, domestic pets, and wild or feral animals, harbour Leptospira in their proximal convoluted tubules of renal nephrons and excrete Leptospira via urine(2). These 
excreted Leptospira enter the human body through abrasions of the skin, mucus membranes or conjunctiva and cause leptospirosis(3). Different mechanisms have been acquired by Leptospira for adaptation to different environments(4).

As leptospirosis is a zoonotic disease transmitted by mammals, birds, rodents and marsupials, people who have direct contact with animals or animal products or reside or work close to animal habitats are considered at risk for infection(2). Hunters(5), sewer workers(6), butchers(7), veterinarians(8) and dairy farmers(9) are reported as major risk groups for the disease through direct exposure to animals, whereas farmers(10) and mine workers $(11,12)$ have exposure via contaminated water sources. Studies have shown that contaminated water is a major source of disease transmission, as the disease is associated with floods, rainfall and recreational activities in water $(13,14)$. Unlike in direct exposure, Leptospira has to enter the host within a short period after being shed into the environment or has to survive in water for a considerable period of time to cause disease by water contamination. Evidence suggests that Leptospira can survive in water for several days to more than one year(15). Additionally, it has been revealed that Leptospira can cause infection in susceptible individuals even after prolonged starvation of the pathogen(15). However, not all people who are exposed to contaminated water develop infection. This phenomenon warrants further exploration of the mechanism of Leptospira transmission.

Sri Lanka is a leptospirosis hotspot $(16,17)$, and the disease causes significant morbidity and mortality despite its underestimation in Sri Lanka $(18,19)$. The major modes of exposure to leptospirosis in Sri Lanka are paddy farming and working in gem mines(20). This finding indicates that indirect exposure through water sources is more common in Sri Lanka than direct exposure to animals. Evidence suggests that the infecting species and clinical patterns of leptospirosis vary among geographical locations in the country(21). This indicates that the natural survival of Leptospira could vary among those areas. There are three major climate zones in Sri Lanka, namely, the wet zone, the dry zone and the intermediate zone(22). The wet zone receives high rainfall on average and frequently reports more leptospirosis cases than other zones, while the dry zone reports leptospirosis cases predominantly during the rainy season(23). Livestock, farming practices and wildlife are also different among these zones. All these factors may lead to varying degrees of Leptospira survival in natural water sources. The objectives of this study are to explore the presence of Leptospira in the environment around human habitats where leptospirosis cases are reported in different climate zones and to perform a time series evaluation of the abundance of Leptospira in natural water sources, the main human-animal interface of disease transmission.

\section{Results}

Water and soil sample collection was performed at 12 sites in nine districts representing five out of the nine provinces of Sri Lanka (Table 1). Of the water samples tested from 12 sites, only the samples from Mawanella (an abundant paddy field) and Mathara (a paddy field) tested positive for Leptospira (Figure 1). 


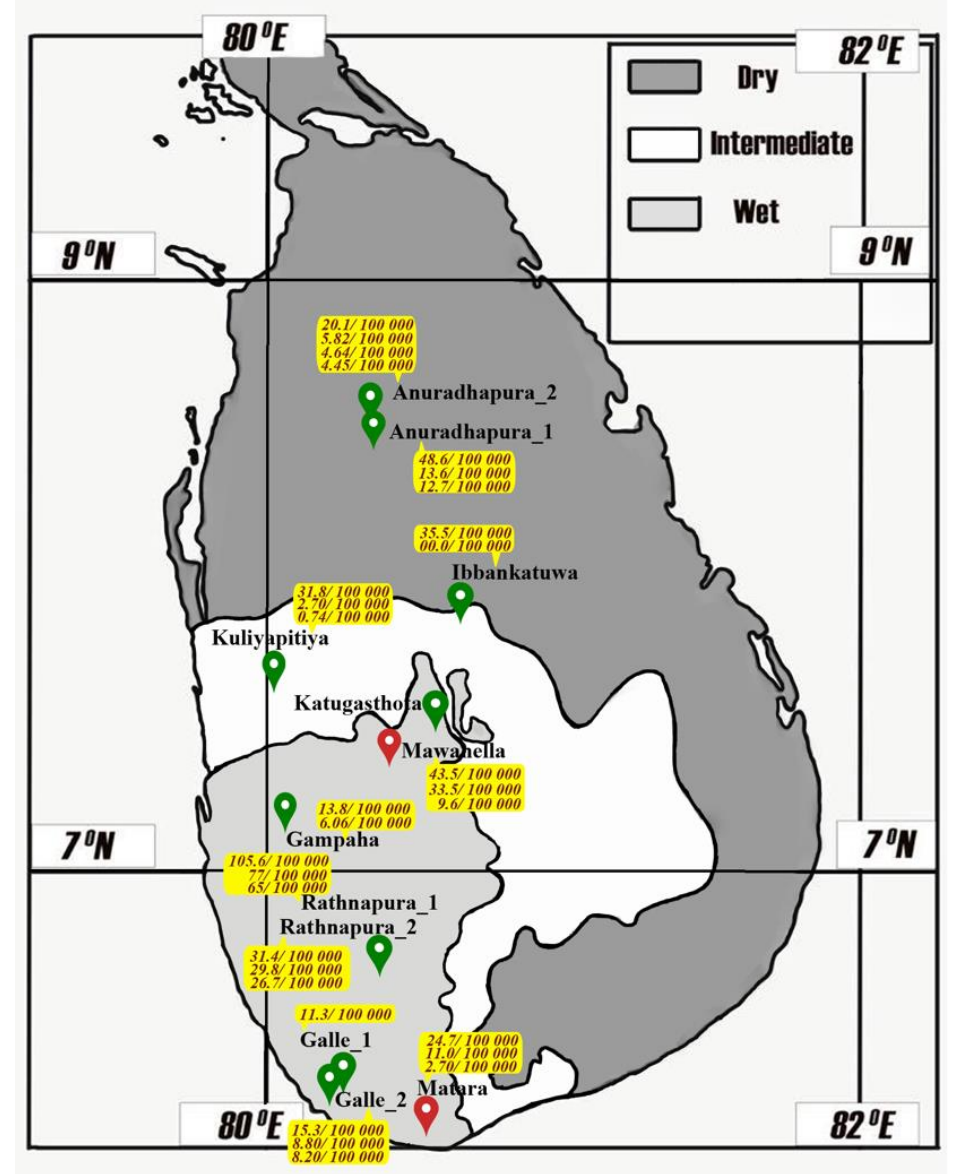

Figure 1: PCR results of pathogenic Leptospira in environmental surface water samples and the relative abundance of the genus Leptospira in the soil microbiome from dry, wet and intermediate zones in Sri Lanka. (Red - PCR-positive water, green PCR-negative water, values within yellow background - relative abundance of the genus Leptospira in soil).

The $16 S$ rRNA amplicon sequencing data were analysed from eleven sites. Taxonomy assigned based on the RefSeq database via MG-RAST showed that in the soil microbiome, the relative abundance of the genus Leptospira was minute compared to that of other organisms. The highest relative abundance (105.6) was reported from the sample of Rathnapura 1 (Figure 1).

The 26 sites included in the second component (dry zone) included water samples from large human-made irrigation tanks/lakes $(n=6)$, paddy fields $(n=6)$, rainwater collections $(n=4)$, rivers/natural water streams $(n=4)$, natural water pools $(n=2)$, water canals $(n=2)$ and wells $(n=2)$. Of these, a single site was strongly positive for Leptospira, while sites 2, 3, 22, 24 and 25 were positive (Figure 2). The strongly positive site 9 was a well from which water was being used for both agriculture and household activities but not for drinking. 
Table 1: Presence of pathogenic Leptospira in environmental surface water samples from dry, wet and intermediate zones in Sri Lanka

\begin{tabular}{|c|c|c|c|c|c|c|}
\hline \multirow{3}{*}{ Sample Name } & \multirow{3}{*}{ Zone } & \multirow{3}{*}{$\begin{array}{l}\text { Site descrip- } \\
\text { tion }\end{array}$} & \multirow{3}{*}{$\begin{array}{l}\text { Water } \\
\text { PCR }\end{array}$} & \multicolumn{3}{|c|}{ Soil } \\
\hline & & & & Sample number & RA*(per & MG-RAST ID \\
\hline & & & & $(\text { PA950_) })^{\#}$ & $100,000)$ & \\
\hline \multirow[t]{3}{*}{ Anuradhapura 1} & \multirow[t]{3}{*}{ Dry } & \multirow{3}{*}{$\begin{array}{l}\text { Bank of a } \\
\text { tank }\end{array}$} & \multirow[t]{3}{*}{ Neg. } & AP1_1 & 13.6 & $\operatorname{mgm} 4919260.3$ \\
\hline & & & & AP2_1 & 48.6 & $\operatorname{mgm} 4919257.3$ \\
\hline & & & & AP1_F06_23_01_2019 & 12.7 & $\operatorname{mgm} 4919246.3$ \\
\hline \multirow[t]{4}{*}{ Anuradhapura 2} & \multirow[t]{4}{*}{ Dry } & \multirow{4}{*}{$\begin{array}{l}\text { Bank of a } \\
\text { tank }\end{array}$} & \multirow[t]{4}{*}{ Neg } & AP3_F05_23_01_2019 & 5.8 & $\operatorname{mgm} 4919241.3$ \\
\hline & & & & AP1_2 & 4.6 & $\operatorname{mgm} 4919261.3$ \\
\hline & & & & AP2_F07_23_01_2019 & 4.4 & mgm4919256.3 \\
\hline & & & & AP2_F04_23_01_2019 & 20.1 & $\operatorname{mgm} 4919245.3$ \\
\hline \multirow[t]{2}{*}{ Ibbankatuwa } & \multirow[t]{2}{*}{$\operatorname{Imdt}^{+}$} & \multirow[t]{2}{*}{ Paddy field } & \multirow[t]{2}{*}{ Neg } & IK5_1_F07 & 35.5 & $\operatorname{mgm} 4919243.3$ \\
\hline & & & & IK1_1_V341F_10 & 0 & mgm4919254.3 \\
\hline Katugasthota & Wet & Water Canal & $\mathrm{Neg}$ & \multicolumn{3}{|c|}{ Soils samples were not taken as the canal is deep } \\
\hline \multirow[t]{3}{*}{ Mawanella } & \multirow[t]{3}{*}{ Wet } & \multirow{3}{*}{$\begin{array}{l}\text { Abundant } \\
\text { paddy field }\end{array}$} & \multirow[t]{3}{*}{ Pos } & MVN3_1_F02_31_01_2019 & 33.5 & $\operatorname{mgm} 4919249.3$ \\
\hline & & & & MVN4_1_F03_31_01_2019 & 43.5 & $\operatorname{mgm} 4919262.3$ \\
\hline & & & & MVN1_1_F01_31_01_2019 & 9.6 & $\operatorname{mgm} 4919269.3$ \\
\hline \multirow[t]{3}{*}{ Rathnapura 1} & \multirow[t]{3}{*}{ Wet } & \multirow[t]{3}{*}{ Gem mine } & \multirow[t]{3}{*}{ Neg } & RT4_1_F10 & 65.0 & $\operatorname{mgm} 4919265.3$ \\
\hline & & & & RT2_1_F09 & 105.6 & $\operatorname{mgm} 4919244.3$ \\
\hline & & & & RT1_1_F08 & 77.0 & $\operatorname{mgm} 4919267.3$ \\
\hline \multirow[t]{3}{*}{ Rathnapura 2} & \multirow[t]{3}{*}{ Wet } & \multirow{3}{*}{ Water canal } & Neg & S25 & 31.4 & $\operatorname{mgm} 4919258.3$ \\
\hline & & & & S24 & 29.7 & $\operatorname{mgm} 4919255.3$ \\
\hline & & & & F07 & 26.7 & mgm4919242.3 \\
\hline Galle 1 & Wet & Water Pit & Neg & S21_F02_new & 11.3 & $\operatorname{mgm} 4919270.3$ \\
\hline Galle 2 & Wet & Paddy field & $\mathrm{Neg}$ & S22_F03_new & 8.8 & $\operatorname{mgm} 4919266.3$ \\
\hline & & & & S20_F01_new & 8.2 & $\operatorname{mgm} 4919252.3$ \\
\hline & & & & S23 & 15.3 & $\operatorname{mgm} 4919264.3$ \\
\hline Mathara & Wet & Paddy field & Pos & F08 & 2.7 & $\operatorname{mgm} 4919251.3$ \\
\hline & & & & F09 & 11.0 & mgm4919250.3 \\
\hline & & & & F10 & 24.7 & mgm4919248.3 \\
\hline Gampaha & Wet & Water Canal & Neg & GP4_1_V341F_09 & 6.0 & $\operatorname{mgm} 4919259.3$ \\
\hline & & & & GP1_1_V341F_08 & 13.8 & $\operatorname{mgm} 4919247.3$ \\
\hline Kuliyapitiya & Imdt & Paddy field & Neg & KU1 & 0.7 & $\operatorname{mgm} 4919253.3$ \\
\hline & & & & KU2 & 0.7 & $\operatorname{mgm} 4919263.3$ \\
\hline & & & & KU4 & 2.7 & mgm4919268.3 \\
\hline
\end{tabular}

+Intermediate Zone, *Relative Abundance, "PA950_ precedes all the sample names, RA-Relative abundance 


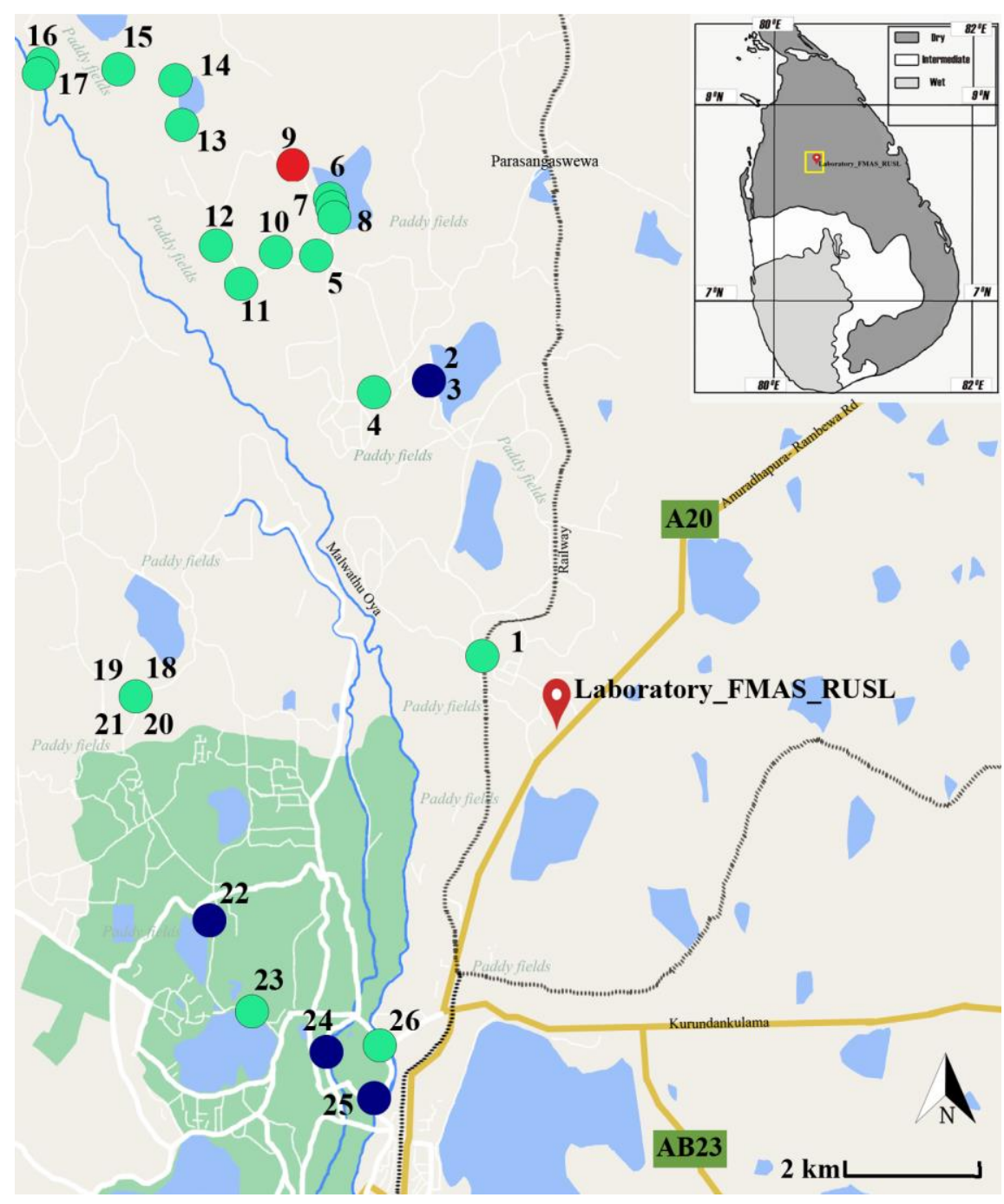

Figure 2: Distribution of sample collection sites and the presence of pathogenic Leptospira in water samples in the dry zone, Sri Lanka. (Green - Negative, Blue - Positive, Red - Strongly positive)

Figures 3-A, B, C, D, and E show the PCR results of five serial samplings of the 10 wells selected for the third component of the study. All the wells were positive in at least one of 
the five serial measurements. A minimum of four wells were positive at any time.

(A) 2019.10.25

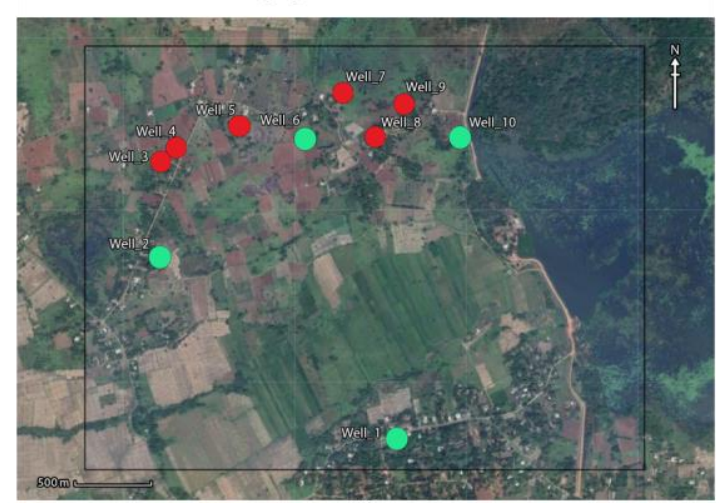

(B) 2019.11.10

(C) 2019.11.25

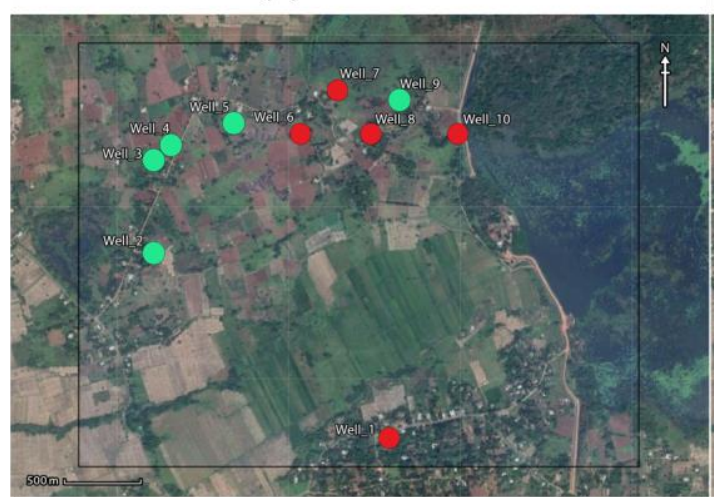

(D) 2019.12.10

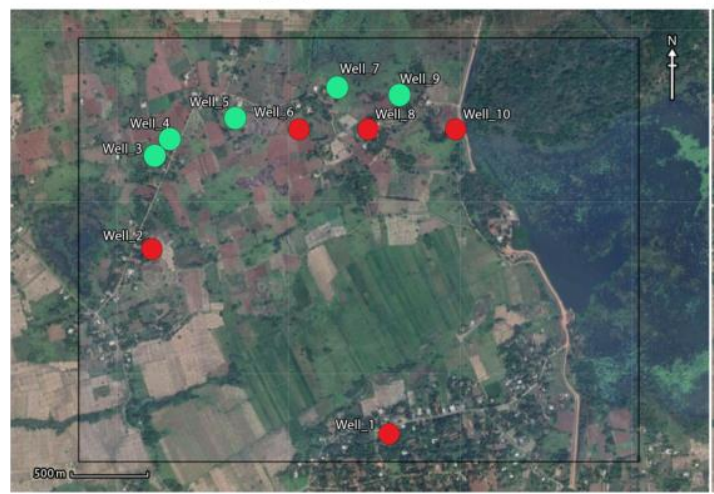

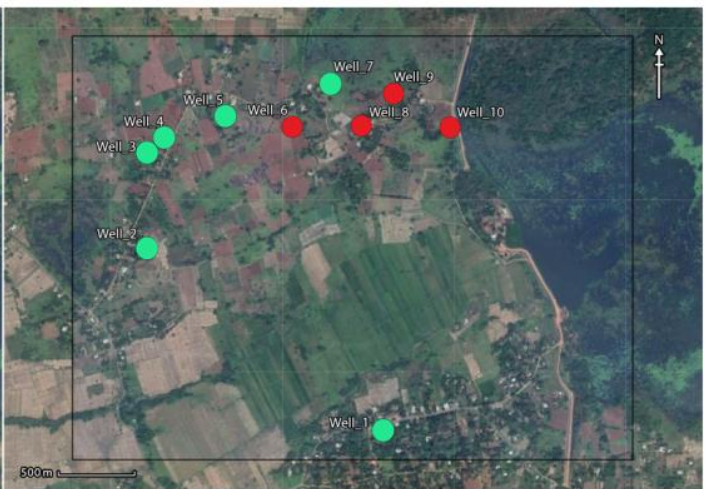

(E) 2020.01.10

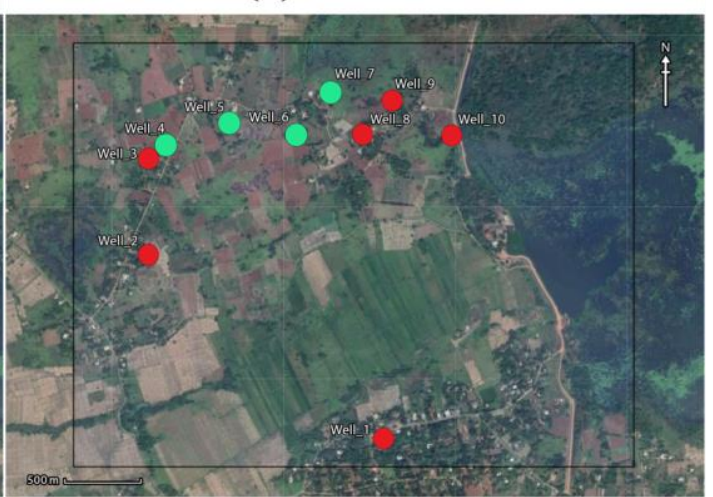

Figure 3: Presence of Pathogenic Leptospira spp. in 10 open wells from the dry zone, Sri Lanka, over a period of 10 weeks. Green-negative, red-positive (Well 9 is the strongly positive well in the second component).

Table 2 summarizes the local and environmental factors associated with the number of times that each well was positive. All the wells shared similar characteristics, while the positivity was higher in the wells situated close to the water tank (lake) and away from the main road. 


\begin{tabular}{llll}
\hline Significant feature & $\begin{array}{l}\text { Subcate- } \\
\text { gory }\end{array}$ & $\begin{array}{l}\text { Mean } \\
\text { positivity }\end{array}$ & p value \\
\hline
\end{tabular}

Local factors of the well

\begin{tabular}{|c|c|c|c|c|}
\hline \multirow{2}{*}{$\begin{array}{l}\text { Built wall above } \\
\text { ground level }\end{array}$} & Yes & 2.29 & \multirow[t]{2}{*}{$t=0.79$} & \multirow[t]{2}{*}{$p=0.44$} \\
\hline & No & 3.00 & & \\
\hline \multirow{2}{*}{$\begin{array}{l}\text { Frequency of well use } \\
\text { per day }\end{array}$} & 1 or less & 2.60 & \multirow[t]{2}{*}{$t=0.23$} & \multirow[t]{2}{*}{$p=0.82$} \\
\hline & 2 or more & 2.40 & & \\
\hline \multirow[t]{2}{*}{ Shed } & Open & 2.20 & \multirow[t]{2}{*}{$t=0.72$} & \multirow[t]{2}{*}{$p=0.48$} \\
\hline & Covered & 2.80 & & \\
\hline \multirow[t]{2}{*}{ Nutrification } & Yes & 2.00 & \multirow[t]{2}{*}{$t=0.98$} & \multirow[t]{2}{*}{$p=0.35$} \\
\hline & No & 2.86 & & \\
\hline
\end{tabular}

\section{Environmental factors of the well}

\begin{tabular}{|c|c|c|c|c|}
\hline \multirow{2}{*}{$\begin{array}{l}\text { Distance from ground } \\
\text { to water level }\end{array}$} & $<1 \mathrm{~m}$ & 2.25 & \multirow[t]{2}{*}{$\mathrm{t}=0.48$} & \multirow{2}{*}{$p=0.64$} \\
\hline & $1 \mathrm{~m}<$ & 2.67 & & \\
\hline \multirow[t]{2}{*}{ Distance to forest } & $<2 \mathrm{~km}$ & 2.83 & \multirow[t]{2}{*}{$\mathrm{t}=1.01$} & \multirow[t]{2}{*}{$\mathrm{p}=0.33$} \\
\hline & $2 \mathrm{~km}<$ & 2.00 & & \\
\hline \multirow{2}{*}{$\begin{array}{l}\text { Distance to paddy } \\
\text { field }\end{array}$} & $<50 \mathrm{~m}$ & 2.50 & \multirow[t]{2}{*}{$t=0.00$} & \multirow[t]{2}{*}{$\mathrm{p}=1.00$} \\
\hline & $50 \mathrm{~m}<$ & 2.50 & & \\
\hline \multirow[t]{2}{*}{ Distance to Chena } & $<50 \mathrm{~m}$ & 2.00 & \multirow[t]{2}{*}{$t=1.2$} & \multirow[t]{2}{*}{$p=0.23$} \\
\hline & $50 \mathrm{~m}<$ & 3.00 & & \\
\hline \multirow{2}{*}{$\begin{array}{l}\text { Distance to nearest } \\
\text { water tank }\end{array}$} & $<800 \mathrm{~m}$ & 3.33 & \multirow[t]{2}{*}{$t=3.19$} & \multirow[t]{2}{*}{$\mathrm{p}=0.01$} \\
\hline & $800 \mathrm{~m}<$ & 1.50 & & \\
\hline \multirow{2}{*}{$\begin{array}{l}\text { Distance from main } \\
\text { road }\end{array}$} & $<1 \mathrm{~km}$ & 1.80 & \multirow[t]{2}{*}{$t=2.53$} & \multirow[t]{2}{*}{$p=0.03$} \\
\hline & $1 \mathrm{~km}<$ & 3.40 & & \\
\hline
\end{tabular}

Figure 4 shows the association between well positivity and distance from the nearest water tank in kilometres. It clearly shows that when the distance from the water tank is reduced, the number of times that the well is positive increases. 


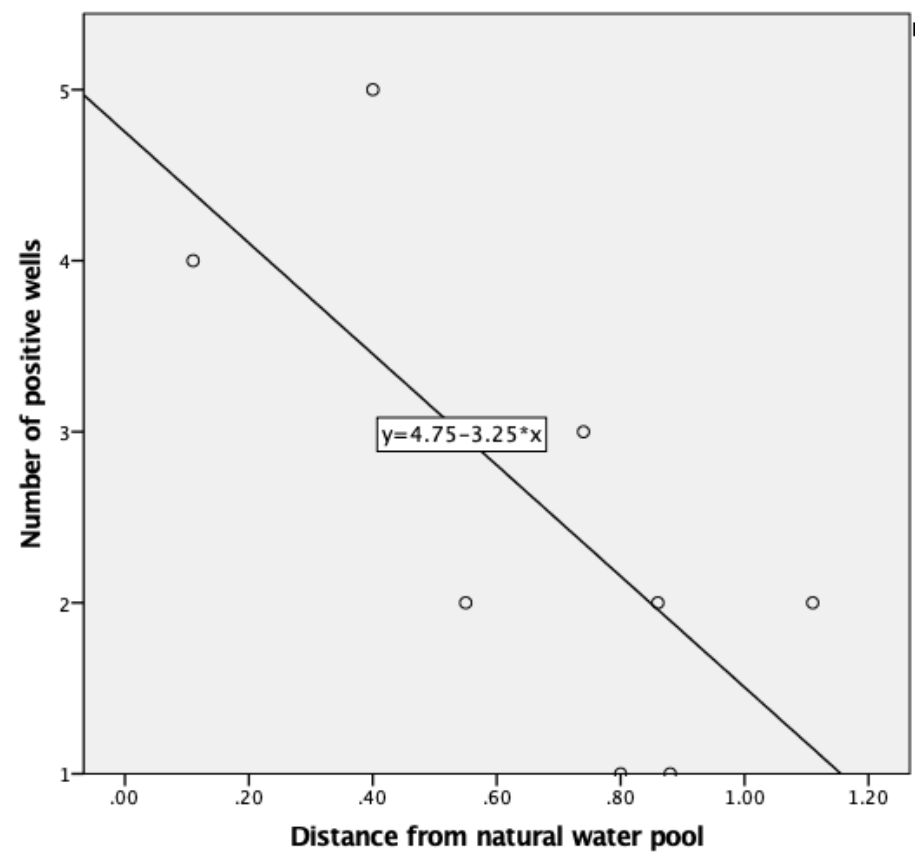

Figure 4 - Association between well positivity and distance from the nearest water pool $(\mathbf{k m})$.

\section{Discussion}

Human leptospirosis is mainly investigated in a disjointed manner, ignoring the zoonotic nature of the disease and the importance of the animal-human interface in disease transmission. Focusing on the transmission process at the animal-human interface is required to explain the disease transmission patterns in zoonotic diseases. Cross-sectional studies with a single time point description of environmental contamination only partially explain the actual risks and transmission pattern of the disease. In this study, we aimed to describe Leptospira in soil and water together with serial sampling of water sources to describe the existence of Leptospira in the natural environment.

With regard to water samples, the finding that two sites in the wet zone were positive while none of the sites in the dry and intermediate zones were positive for Leptospira is compatible with the reported incidence of leptospirosis, as the wet zone reports nearly two times the number of cases compared to that in the dry zone(24). As the environment of the wet zone is favourable for the growth and survival of Leptospira, the probability of detecting the organism in samples is expected to be higher. The observed difference could also be due to the diversity of Leptospira in different geographical areas, as described previously(25). It has been shown that Leptospira can survive in vitro as well as in the natural environment through biofilm formation with the environmental microbiota. Therefore, Leptospira can survive even in nutrient-free environments(26,27). On the other hand, the nutrients required for Leptospira survival could be different in the two climatic zones, and further studies are needed to explain the differences we observed. Nutrient availability could be a main reason for the observed diversities of water samples between the climate zones. The diversity of the soil microbiome may be a contributory factor to the differences we observed, as shown in the $16 \mathrm{~S}$ amplicon sequencing data of the soil samples tested at 
the same sites(28). Species- or strain-specific differences in the natural survival of Leptospira, with a specific focus on geographical, environmental and climatic factors, need further exploration(15).

An emerging hypothesis is that virulent Leptospira survive in soil for a long period and come to the surface when the soil is washed away during the rainy season $(15,29,30)$. Therefore, the probability of detecting Leptospira could be higher in wet zone due to its surface wetness throughout the year. In the dry zone, relatively low rainfall is received for a short period of time (22), and during the non-rainy season, the lands become completely dry, making them unfavourable for the growth and survival of Leptospira. Leptospirosis outbreaks occur predominantly during the rainy season in the dry zone. Although this study was conducted during the rainy season, the presence of Leptospira in the dry zone was still less frequent than that in the wet zone. With $16 S$ amplicon sequencing, the genus Leptospira was detected from the soil samples at all 10 sites. Negativity of the water samples but positivity of the soil samples could support the emerging hypothesis of a higher abundance of Leptospira in soil than in water $(15,29,30)$. However, the genus Leptospira detected in soil samples includes both pathogenic and non-pathogenic species, although the primer used for PCR specifically targeted pathogenic Leptospira. Nevertheless, the observed difference may have been due to the different techniques that we performed for soil and water, which is a major consideration when interpreting the findings. To transmit Leptospira from the environment to humans, a satisfactory concentration of Leptospira is needed in the environment at the time of contact with the potential host. Therefore, the very low concentration of Leptospira in both soil and water in random samples may explain the necessity of acute exposure to an environment containing Leptospira for human transmission. This highlights the importance of exposure to Leptospira-containing animal urine shortly after excretion in order to consider the environment infectious for human transmission at the time of contact between the environment and humans.

In the second component, there was only one strong positive result, which was in an uncovered well. This finding is compatible with some of the previous knowledge stating that the isolation rate of Leptospira is higher in stagnated water than in running water(15). This finding further confirms the randomness of Leptospira in the dry zone. Only a single well provided positive results throughout the serial testing (third component). Although the evidence suggests that some of the species can survive up to one year in the natural environment, our observation indicates a short lifecycle for Leptospira in the selected water source(15). However, the theoretical possibility of a non-even distribution of Leptospira in well water could have led to the non-inclusion of Leptospira in the obtained water sample, incorrectly leading to the finding of a short life span of the organism. This preliminary observation indicates that in-depth exploration of the physical and chemical qualities of water with serial samples are required to understand Leptospira survival in water. However, recontamination between samplings will be a major confounding effect and must be avoided in future studies. Together with this observation, we noted that distance from main roads was also associated with positivity, which also supports the hypothesis of 
more frequent contamination by feral animals. A higher positive rate closer to water pools indicates an association of leptospirosis with aquatic environments. This is compatible with the findings of a systematic review published by Mwanajaa et al., where most waterrelated activities were identified as significant risk factors for leptospirosis(2).

The intermittent nature of positivity could be better explained by repetitive contamination by the contaminated urine of animals. The ecological system in Sri Lanka allows domesticated animals, livestock and feral animals to be mixed frequently, and in the study area, numerous rodent species are abundant. This is compatible with the findings highlighted by Vincent et al. in 2019, where they stated that repetitive exposure could be a main risk factor for Leptospira infection(31). Further, the authors highlighted the difficulty of obtaining definitive proof regarding the source of contamination of the environment through field studies. As the source of infection is best detected by investigating reservoirs, further studies targeting animals, humans and the environment and interactions between them are important to prevent the disease.

If leptospirosis occurs via organisms surviving in the natural environment for a long duration, a preventive method could be planned to inhibit the growth and survival of Leptospira within the natural environment. The finding of this research that there is no prolonged survival of Leptospira in the environment makes environmental prevention cumbersome. Recent environmental contamination with infected reservoir host urine before human exposure seems to be essential for leptospirosis in humans. In the absence of a port of entry, such as an abrasion, a laceration or a wound, a strong immune response also contributes to/protects against the occurrence of leptospirosis, even after exposure. The epidemiological triad is a concept of breaking the links between agents, hosts and environments for the prevention of communicable diseases. Therefore, we emphasize the random presence of Leptospira in the environment as a major component of this epidemiological triad (Figure 5) to explain why all people who share the same exposure do not get the infection. 


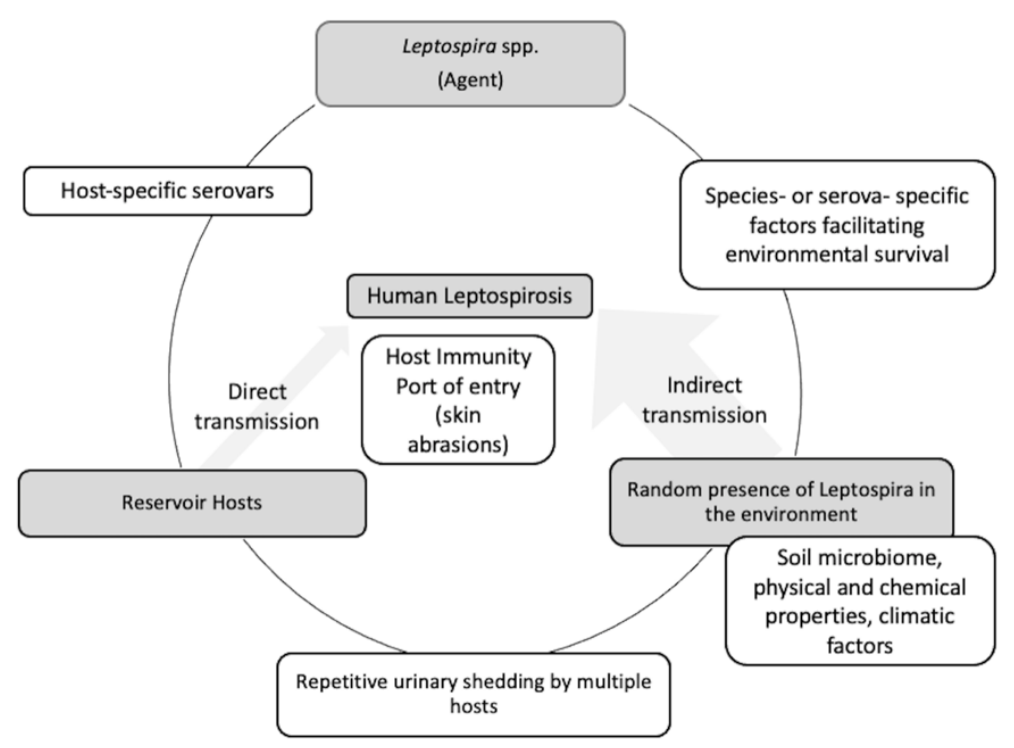

Figure 5. Proposed explanatory model for the random transmission of pathogenic Leptospira from a single source (using the epidemiological triad)

Prophylactic therapy with doxycycline is the only preventive method recommended globally, despite the lack of evidence to support its use(32). This hypothetical model provides an understanding of the different opportunities to search for new preventive methods for leptospirosis. Novel studies on the prevention of leptospirosis via changes in soil abundance, biological prevention, prevention through environmental toxins, avoiding entry to the body and changing the host response by immune modulation can be explored as new avenues of leptospirosis prevention research in the future.

\section{Limitations}

The sensitivity of PCR is considered low when the concentration of Leptospira is low(33). As Leptospira is diluted in water, there is a high probability of failing to detect the existing Leptospira from the source of water collection. We used a 2-step centrifugation protocol to concentrate Leptospira. Although it was an optimized procedure, there was a probability of losing a considerable number of Leptospira in the pellet of the $1^{\text {st }}$ centrifugation step. Metagenomic analysis is highly dependent on the database used. Therefore, we accept that there is a probability of missing species of the genus Leptospira that are not present in the MG-RAST database. Direct comparison of the abundances of Leptospira in water and soil could not be performed, as two different analysis techniques were used. Although the PCR was negative, there was a theoretical possibility of Leptospira being present in place with the same water collection other than the site of sample collection.

\section{Materials and Methods}

\section{Study design and setting}

This study included three major components of environmental sample collections, as illustrated in Figure 6: island-wide (including most parts of the island) water and soil 
sample collection, dry zone water sample collection and serial sampling of water samples from ten open wells at five different time points. The first component had two subcomponents: water sample analysis and soil sample analysis. For the water samples, purposive sampling of water sources was conducted at 12 sites representing all three climatic zones: dry, wet and intermediate. As shown in Table 1, soil samples were collected from the same eleven sites where the water samples had been collected. Site Katugasthota (Figure 1) was a deep canal where we collected only water due to the practical inconvenience of soil sample collection. All sites were selected on the basis of probable exposure history of confirmed patients with leptospirosis. The second component included sample collection in the dry zone. For the second component, water collection sites near human habitats were selected using a purposive sampling technique (Figure2). The Public Health Research Laboratory of the Faculty of Medicine and Allied Sciences, Rajarata University of Sri Lanka (FMAS_RUSL), was selected as the initial point, and twenty-six nearby sites were selected considering a higher possibility of human contact. The dry zone was selected over the wet zone for the second component considering the rareness of Leptospira, as there were no positive sites in the dry zone in the first component of the study. Site number nine (a well), part of the second component, was selected as the initial point of the third component. Another nine wells (10 wells in total) from the close locality of site number nine of the second component were selected for serial sampling of the third component. Serial sampling was conducted at 2-week intervals four times, and the fifth sampling was conducted 4 weeks after the fourth sampling (Figure 3).

Component 1: PCR testing of the water and 16s amplicon sequencing of soil from possible exposure sites of confirmed cases of leptospirosis in dry, intermediate and wet zones.

Component 2: PCR testing of the water samples collected from the surface water bodies (rain water collections, lakes, rivers, paddy fields) situated closer to human habitats in dry zone.

Component 3: Serial sample testing of 10 open wells using the positive well from component 2 as the starting point: 4 samples with two weeks interval and the final sample after a 4 weeks interval.

Figure 6 - Study flow chart of sampling process of the three components of the study 


\section{Sample collection and transport}

Four water samples were collected from each site, and a 1-metre gap was maintained between the sample collection locations within the sites. Ten millilitres of water was collected in a sterile $15 \mathrm{ml}$ Falcon tube using a clean plastic container, and the lid was closed immediately. Samples were transported on ice packs to the Public Health Research Laboratory of the Faculty of Medicine and Allied Sciences, Rajarata University of Sri Lanka, within 48 hours of collection. For the soil samples, four samples were collected from each site, maintaining a one-metre gap between the sample collection locations within the site. Samples were collected into a clean container using a clean spoon. The samples were transported the same way as the water samples. Eighteen samples from wet zone (8 sites), five samples from intermediate zone ( 2 sites) and seven samples from dry zone ( 2 sites) were sent for metagenomic analysis.

\section{Sample Processing, DNA extraction and PCR testing}

There is no optimized best method for concentrating Leptospira from water samples(34,35). We found that a two-step protocol suggested by Paula et al. to concentrate Leptospira from urine produced better results than the available protocols for water(36). Therefore, centrifugation was conducted in two steps. First, samples were centrifuged at $3000 \mathrm{rpm}$ for 5 minutes. Second, each supernatant was transferred to two microcentrifuge tubes $(1.5 \mathrm{~mL})$ and centrifuged at $15000 \mathrm{rpm}$ for 10 minutes, and the supernatants were discarded. Samples collected from the same sites were pooled for the extraction of DNA. DNA was extracted using a QIAamp DNA Blood Mini Kit (Qiagen, USA) according to the manufacturer's instructions. The pathogen-specific rRNA 16S-1 primer pair used for this study was described in a previous study as 16-1 F 5'-GCG TAG GCG GAC ATG TAA GT-3' and 16-1 R 5'-AAT CCC GTT CAC TAC CCA CG-3'(37). qPCR was performed using the CFX96 real-time PCR detection system (Bio-Rad, US) with the following thermal cycle conditions: $95^{\circ} \mathrm{C}$ for 5 minutes, 45 cycles of $\left[94^{\circ} \mathrm{C}\right.$ for $30 \mathrm{~s}, 60^{\circ} \mathrm{C}$ for $30 \mathrm{~s}$, followed by melt curve generation from $65^{\circ} \mathrm{C}$ to $90^{\circ} \mathrm{C}$ performed at an increment of $0.5^{\circ} \mathrm{C}$ per cycle. The PCR volumes were as follows. For each reaction well, $10 \mu \mathrm{L}$ of SYBR Green Fast Mix (Quantabio, USA), $5 \mu \mathrm{L}$ of DNA template, and $0.02 \mu \mathrm{L}$ of each diluted forward and reverse primer were added. The total reaction volume was adjusted to $20 \mu \mathrm{L}$ by adding PCRgrade water. The final concentration of each primer was $0.1 \mu \mathrm{M}$.

\section{Definition of PCR positivity}

A positive curve with melting temperature was considered a positive replicate.

If only one replicate was positive, the sample was considered positive. If two or more replicates were positive, the site was considered strongly positive.

\section{$16 S$ Amplicon sequencing of soil}

Next-generation sequencing was performed at a commercial facility(38). Bacterial $16 \mathrm{~S}$ rRNA amplicon sequencing was performed by Ion Torrent to detect the microbiota of the soil. DNA extraction was performed using a soil-specific QIAAmp ${ }^{\circledR}$ DNA Mini Kit 
(Qiagen) according to the manufacturer's instructions. The 16S rRNA gene V1-V2 region was used first to confirm the presence of bacteria. PCR amplification was performed in a $25 \mu \mathrm{l}$ mixture containing $12.5 \mu \mathrm{l}$ of Platinum ${ }^{\circledR}$ PCR Supermix (Invitrogen), $12.5 \mu \mathrm{M}$ each primer and $3.75 \mu \mathrm{l}$ of template DNA. Sequencing of the final libraries and template preparation were performed using the PGM ${ }^{\mathrm{TM}} \mathrm{Hi}-\mathrm{Q}^{\mathrm{TM}} \mathrm{OT} 2 \mathrm{Kit}$ (Thermo Fisher Scientific) and Ion PGM ${ }^{\mathrm{TM}} \mathrm{Hi}-\mathrm{Q}^{\mathrm{TM}}$ Sequencing Kit (Thermo Fisher Scientific) according to the manufacturer's instructions. Barcoded bacterial libraries were multiplexed on a single chip in a 400 bp run to obtain sequencing data. Bioinformatic analysis was performed by the investigators by uploading raw fastq data to Metagenome Rapid Annotation using the Subsystem Technology (MG-RAST) server(39).

\section{Data analysis}

The total number of times that a well was positive out of five measurements was considered the dependent variable. Wells were categorized into two groups based on the presence or absence of the risk factors shown in Table 2. Two-sample t tests were used to compare the number of positive risk factors present and the number of risk factors absent. A $P$ value less than 0.05 was considered significant.

Supplementary Materials: The following are available online at www.mdpi.com/xxx/s1. Figure 1: PCR results of pathogenic Leptospira in environmental surface water samples and the relative abundance of the genus Leptospira in the soil microbiome from dry, wet and intermediate zones in Sri Lanka. (Red - PCR-positive water, green - PCR-negative water, values within the yellow background - relative abundance of the genus Leptospira in soil). Figure 2: Distribution of sample collection sites and the presence of pathogenic Leptospira in water samples in the dry zone, Sri Lanka. Figure 3: Presence of pathogenic Leptospira spp. in 10 open wells from the dry zone, Sri Lanka, over a period of 10 weeks. Green-negative, red-positive (Well 9 was the strongly positive well in the second component). Figure 4: Association between well positivity and distance from the nearest water pool $(\mathrm{km})$. Figure 5: Proposed explanatory model for the random transmission of pathogenic Leptospira from a single source (using the epidemiological triad). Table 1: Presence of pathogenic Leptospira in environmental surface water samples from dry, wet and intermediate zones in Sri Lanka. Table 2: Local and environmental risk factors for well positivity.

Author Contributions: Conceptualization, J.W. and S.A.; Methodology, J.W., S.S., A.N. and S.A.; Validation of the Investigation, J.W., S.S., I.S. and C.K.; Formal Analysis, J.W. ; Investigation, N.F., C.K., I.S.; Resources, J.W., S.A.; Data Curation, J.W., N.F., A.N.; Writing - Original Draft Preparation, J.W., S.S.; Writing - Review \& Editing, J.W., S.A., I.S.; Supervision, S.A.; Project Administration, N.F.; Funding Acquisition, J.W., S.A."

Funding: SA, JW and IS are partially supported by US Public Service Grant U19AI115658.

The sample analysis was funded through the Faculty of Medicine and Allied Sciences annual publication award received by the first and last authors. All the other costs are self-funded.

Institutional Review Board Statement: Not applicable.

Data Availability Statement: All epidemiological data from the $3^{\text {rd }}$ component have been deposited at $10.5281 /$ zenodo.4483786.

All metagenomic data can be accessed through MG-RAST IDs. 


\begin{abstract}
Acknowledgments: We acknowledge all technical staff who worked in the Public Health Research Laoratory of the Faculty of Medicine and Allied Sciences, Rajarata University of Sri Lanka; Dr. Gihan Rathnayaka and Dr. Hasantha Banduwardana for graphic design; and all the owners of the wells in the $3^{\text {rd }}$ component of the study.
\end{abstract}

Conflicts of Interest: The authors declare no conflicts of interest.

\title{
References
}

1. Rabinowitz PM, Kock R, Kachani M, Kunkel R, Thomas J, Gilbert J, et al. Toward Proof of Concept of a One Health Approach to Disease Prediction and Control. Emerg Infect Dis. 2013;19. doi:10.3201/eid1912.130265.

1. 2. Mwachui MA, Crump L, Hartskeerl R, Zinsstag J, Hattendorf J. Environmental and Behavioural Determinants of Leptospirosis Transmission: A Systematic Review. PLoS Negl Trop Dis. 2015;9:e0003843. doi:10.1371/journal.pntd.0003843.

2. 3. Faine S. Leptospira and leptospirosis. Leptospira and leptospirosis. 1994. https://www.cabdirect.org/cabdirect/abstract/19952009809. Accessed 29 Oct 2017.

3. 4. Evangelista K V, Coburn J. Leptospira as an emerging pathogen: a review of its biology, pathogenesis and host immune responses. Future Microbiol. 2010;5:1413-25.

4. 5. Deutz A, Fuchs K, Schuller W, Nowotny N, Auer H, Aspöck H, et al. [Seroepidemiological studies of zoonotic infections in hunters in southeastern Austria--prevalences, risk factors, and preventive methods]. Berl Munch Tierarztl Wochenschr. 2003;116:306-11. http://www.ncbi.nlm.nih.gov/pubmed/12894685. Accessed 28 Jan 2021.

5. 6. Ambekar AN, Bharadwaj RS, Joshi SA, Kagal AS, Bal AM. Sero surveillance of leptospirosis among sewer workers in Pune. Indian J Public Health. 2004;48:27-9. http://www.ncbi.nlm.nih.gov/pubmed/15704723. Accessed 28 Jan 2021.

6. 7. Esmaeili S, Naddaf SR, Pourhossein B, Hashemi Shahraki A, Bagheri Amiri F, Gouya MM, et al. Seroprevalence of Brucellosis, Leptospirosis, and Q Fever among Butchers and Slaughterhouse Workers in South-Eastern Iran. PLoS One. 2016;11:e0144953. doi:10.1371/journal.pone.0144953.

7. 8. Sanhueza JM, Heuer C, Wilson PR, Benschop J, Collins-Emerson JM. Prevalence and risk factors for Leptospira exposure in New Zealand veterinarians. Epidemiol Infect. 2015;143:2116-25. doi:10.1017/S0950268815000515.

8. 9. Yupiana Y, Vallee E, Wilson P, Collins-Emerson J, Weston J, Benschop J, et al. Emerging Leptospira strain poses public health risk for dairy farmers in New Zealand. Prev Vet Med. 2019;170:104727. doi:10.1016/j.prevetmed.2019.104727.

9. 10. Sahneh E, Delpisheh A, Sayehmiri K, Khodabakhshi B, Moafi-Madani M. Investigation of Risk Factors Associated with Leptospirosis in the North of Iran (2011-2017). J Res Health Sci. 2019;19:e00449. http://www.ncbi.nlm.nih.gov/pubmed/31278217. Accessed 28 Jan 2021.

10. 11. Warnasekara J, Aberathna P, Nanayakkara G, Vinetz J, Agampodi S. Improving the leptospirosis disease burden assessment by including ambulatory patients from outpatient departments: a cross-sectional study. F1000Research. 2020;9:1129. doi:10.12688/f1000research.26202.1.

11. 12. Parveen SMA, Suganyaa B, Sathya MS, Margreat AAP, Sivasankari K, Shanmughapriya S, et al. Leptospirosis Seroprevalence Among Blue Metal Mine Workers of Tamil Nadu, India. Am J Trop Med Hyg. 2016;95:38-42. doi:10.4269/ajtmh.16-0095.

12. 13. Agampodi SB, Karunarathna D, Jayathilala N, Rathnayaka H, Agampodi TC, Karunanayaka L. Outbreak of leptospirosis after white-water rafting: sign of a shift from rural to recreational leptospirosis in Sri Lanka? Epidemiol Infect. 2014;142:843-6. doi:10.1017/S0950268813001465.

13. 14. Bandara M, Ananda M, Wickramage K, Berger E, Agampodi S. Globalization of leptospirosis through travel and migration. Global Health. 2014;10:61. doi:10.1186/s12992-014-0061-0.

14. 15. Bierque E, Thibeaux R, Girault D, Soupé-Gilbert ME, Goarant C. A systematic review of Leptospira in water and soil environments. PLoS One. 2020.

15. 16. Costa F, Hagan JE, Calcagno J, Kane M, Torgerson P, Martinez-Silveira MS, et al. Global Morbidity and Mortality of Leptospirosis: A Systematic Review. PLoS Negl Trop Dis. 2015;9:e0003898.

16. 17. Torgerson PR, Hagan JE, Costa F, Calcagno J, Kane M, Martinez-Silveira MS, et al. Global Burden of Leptospirosis: Estimated in Terms of Disability Adjusted Life Years. PLoS Negl Trop Dis. 2015;9:e0004122. doi:10.1371/journal.pntd.0004122.

17. 18. Warnasekara J, Koralegedara I, Agampodi S. Estimating the burden of leptospirosis in Sri Lanka; a systematic review. BMC Infect Dis. 2019;19:119. doi:10.1186/s12879-018-3655-y.

18. 19. Warnasekara JN, Agampodi S. Leptospirosis in Sri Lanka. Sri Lankan J Infect Dis. 2017;7:67. doi:10.4038/sljid.v7i2.8155.

19. 20. Agampodi SB, Agampodi TC, Thalagala E, Perera S, Chandraratne S, Fernando S. Do People Know Adequately about Leptospirosis? A Knowledge Assessment Survey in Post-outbreak Situation in Sri Lanka. Int J Prev Med. 2010;1:158-63. http://www.pubmedcentral.nih.gov/articlerender.fcgi?artid=3075525\&tool=pmcentrez\&rendertype=abstract. Accessed 8 Feb 2016.

20. 21. Agampodi SB, Dahanayaka NJ, Bandaranayaka AK, Perera M, Priyankara S, Weerawansa P, et al. Regional differences of leptospirosis in Sri Lanka: observations from a flood-associated outbreak in 2011. PLoS Negl Trop Dis. 2014;8:e2626. doi:10.1371/journal.pntd.0002626.

21. 22. Meteorology department, Sri Lanka. http://www.meteo.gov.lk/index.php?lang=en. Accessed 12 Oct 2019.

22. 23. Agampodi SB. Spatial epidemiology of leptospirosis in Sri Lanka. Epidemiol Infect. 2012;140:1530-1; author reply 1531-2. doi:10.1017/S0950268811002512.

23. 24. Epidemiology Unit, Sri Lanka. http://www.epid.gov.lk/web/index.php?lang=en. Accessed 12 Oct 2019. 
24. 25. Agampodi SB, Dahanayaka NJ, Bandaranayaka AK, Perera M, Priyankara S, Weerawansa P, et al. Regional differences of leptospirosis in Sri Lanka: observations from a flood-associated outbreak in 2011. PLoS Negl Trop Dis. 2014;8:e2626. doi:10.1371/journal.pntd.0002626.

25. 26. VA B, ME M, A T, S Z, RA H, DA H, et al. Interactions of Leptospira with environmental bacteria from surface water. Curr Microbiol. 2011;62. doi:10.1007/S00284-011-9931-3.

26. 27. P R, P B, S K, C S, MC P, W L, et al. Biofilm formation by saprophytic and pathogenic leptospires. Microbiology. 2008;154 Pt 5. doi:10.1099/MIC.0.2007/014746-0.

27. 28. Thibeaux R, Geroult S, Benezech C, Chabaud S, Soupé-Gilbert M-E, Girault D, et al. Seeking the environmental source of Leptospirosis reveals durable bacterial viability in river soils. PLoS Negl Trop Dis. 2017;11. doi:10.1371/JOURNAL.PNTD.0005414.

28. 29. Schneider AG, Casanovas-Massana A, Hacker KP, Wunder EA, Jr., Begon M, et al. Quantification of pathogenic Leptospira in the soils of a Brazilian urban slum. PLoS Negl Trop Dis. 2018;12. doi:10.1371/JOURNAL.PNTD.0006415.

29. 30. Vincent AT, Schiettekatte O, Goarant C, Neela VK, Bernet E, Thibeaux R, et al. Revisiting the taxonomy and evolution of pathogenicity of the genus Leptospira through the prism of genomics. PLoS Negl Trop Dis. 2019;13. doi:10.1371/JOURNAL.PNTD.0007270.

30. 31. Brett-Major DM, Lipnick RJ. Antibiotic prophylaxis for leptospirosis. Cochrane Database Syst Rev. 2009. doi:10.1002/14651858.CD007342.pub2.

31. 32. Backstedt BT, Buyuktanir O, Lindow J, Wunder EA, Reis MG, Usmani-Brown S, et al. Efficient detection of pathogenic leptospires using 16S ribosomal RNA. PLoS One. 2015.

32. 33. Credence Genomics I DNA testing Genomics Bioinformatics. https://www.credencegenomics.com/. Accessed 25 Jan 2021.

33. 34. Meyer F, Paarmann D, D'Souza M, Olson R, Glass EM, Kubal M, et al. The metagenomics RAST server - A public resource for the automatic phylogenetic and functional analysis of metagenomes. BMC Bioinformatics. 2008;9:1-8. 